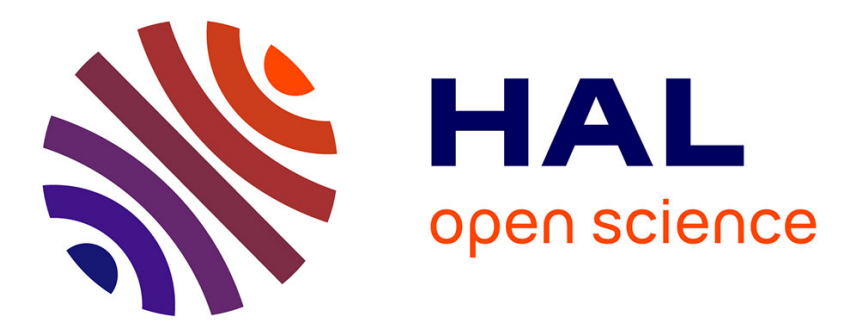

\title{
Prediction of surface integrity using Flamant-Boussinesq analytical model
}

Thomas Baizeau, Frédéric Rossi, Gérard Poulachon, José Outeiro

\section{To cite this version:}

Thomas Baizeau, Frédéric Rossi, Gérard Poulachon, José Outeiro. Prediction of surface integrity using Flamant-Boussinesq analytical model. CIRP Annals - Manufacturing Technology, 2016, 65 (1), pp.81-84. 10.1016/j.cirp.2016.04.043 . hal-01361335

\section{HAL Id: hal-01361335 \\ https://hal.science/hal-01361335}

Submitted on 7 Sep 2016

HAL is a multi-disciplinary open access archive for the deposit and dissemination of scientific research documents, whether they are published or not. The documents may come from teaching and research institutions in France or abroad, or from public or private research centers.
L'archive ouverte pluridisciplinaire HAL, est destinée au dépôt et à la diffusion de documents scientifiques de niveau recherche, publiés ou non, émanant des établissements d'enseignement et de recherche français ou étrangers, des laboratoires publics ou privés. 


\title{
Prediction of surface integrity using Flamant-Boussinesq analytical model
}

\author{
Thomas Baizeau*, Frédéric Rossi, Gérard Poulachon (2), José Carlos Outeiro (2) \\ Arts et Metiers ParisTech, LaBoMaP, Rue porte de Paris, 71250 Cluny, France
}

A R T I C L E I N F O

\section{Keywords:}

Surface integrity

Hard machining

Predictive model

\begin{abstract}
A B S T R A C T
Surface integrity prediction of hard machining using PCBN cutting tools remains a major topic for many high value added applications. A Flamant-Boussinesq (FB) analytical model has initially been applied for surface integrity prediction in orthogonal cutting. In order to extend this model to the general case of 3D cutting process, a cutting force model was developed and incorporated into the FB model. This one was then used to evaluate the plastically deformed layer thickness induced by 3D round cutting tools. It was validated by comparing the predicted plastic strains with the micro hardness distribution induced by 3D cutting tests.
\end{abstract}

\section{Introduction}

Surface integrity induced by material removal processes remains a challenge for predicting the functional performance and lifetime of components [1]. Despite that the residual stress state in the machined surface and subsurface is the most studied parameter, a good knowledge of the remaining plastic strain beneath the surface after a cutting operation, is a key factor to set the next production step in order to improve the surface integrity.

The combination of Digital Image Correlation (DIC) with the development of ultra-high speed cameras opens new avenues for recording strain fields during orthogonal cutting [2], and consequently to get access to the surface integrity [3] by using numerical modelling. However, this method has not yet been used to $3 \mathrm{D}$ operation using a round insert.

This research proposes an hybrid approach by combining the commonly used edge discretisation method on forces [4,5] with the Flamant-Boussinesq (FB) analytical model [6,7] and the kinematic (displacement and strain) field measurement performed by DIC.

To validate this approach, the plastically deformed layer thickness was extracted from the model and compared to the corresponding thickness obtained experimentally. This thickness was estimated with micro-hardness tests conducted at different cross-sections of the machined specimen.

\section{Experimental and modelling procedures}

\subsection{Work material, cutting tools and parameters}

Cutting tests were performed on an AISI 52100 hardened bearing steel according to the ISO 683-17 standard [8]. The $35(L) \times 15(w) \times 1.5 / 4.5(t) \mathrm{mm}$ specimens have been extracted in a

\footnotetext{
* Corresponding author.

E-mail address: thomas.baizeau@ensam.eu (T. Baizeau).
}

hardened tube heat treated at $850^{\circ} \mathrm{C}$, quenched in hot oil and tempered at $110{ }^{\circ} \mathrm{C}$ during $60 \mathrm{~min}$. The work material presents ultra-fine carbides spread in a $60 \%$ martensitic and $40 \%$ bainitic structure with an average grain size of $5 \mu \mathrm{m}$. A $610 \pm 15 \mathrm{HV}_{0.1}$ average hardness was measured with a Wilson Tukon 1202 microhardness tester. A new specimen was employed for each cutting condition.

Two inserts references CCGW060202 (rectilinear edge) and RNGN090300B (round edge) provided by Sumitomo were used for orthogonal cutting and 3D-planing tests, respectively. The substrate is composed by $70 \%$ of c-BN ( $4 \mu \mathrm{m}$ of particle size) embedded in a TiN binder (Sumitomo BNC200 grade). Both inserts have an $19 \pm 5 \mu \mathrm{m}$ edge radius, $r_{\beta}, \mathrm{a}-20^{\circ}$ rake angle, $\gamma$, and a $7^{\circ}$ clearance angle, $\alpha$, after mounted in the tool holder (in the toolin-hand system according to the ISO 3002 standard [9]). For the whole study, the cutting speed has been selected to $90 \mathrm{~m} / \mathrm{min}$ based on a prior tool-life and a work material/cutting tool pair investigation. For the orthogonal cutting, presented in Fig. $1 \mathrm{a}$, the width of cut, $b$, is

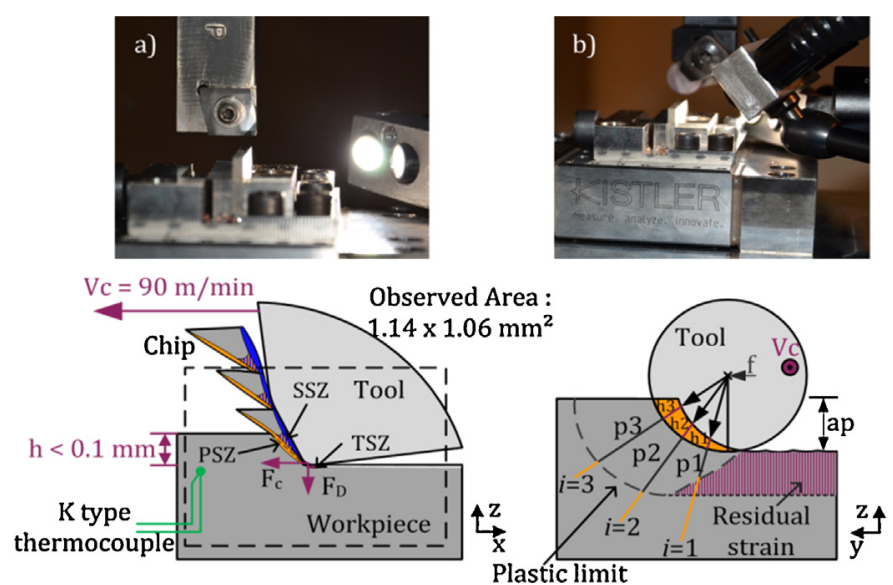

Fig. 1. Cutting tests configurations: (a) orthogonal cutting with linear cutting edge and (b) 3D-planing with round cutting edge. 
equal to the width of the specimen $(b=1.5 \mathrm{~mm}$ ) [10]. The uncut chip thickness, $h$, was selected ranging from 0.01 to $0.1 \mathrm{~mm}$ with a step of $0.01 \mathrm{~mm}$. These values are in the range of the evolution of the uncut chip thickness obtained in 3D-planing configuration (Fig. 1b). For the 3D-planing tests, the feed, $f$, and the depth of cut, $a_{p}$, were kept constant and both equal to $0.2 \mathrm{~mm}$. The feed values covered an uncut chip thickness ranging from 0 to $0.07 \mathrm{~mm}$. Each set of conditions were repeated three times on a DMG DMC85V milling machine.

\subsection{Experimental set-up and parameters}

The cutting speed is obtained by the translation of the $x$-axis powered by linear motors enabling to reach up to $120 \mathrm{~m} / \mathrm{min}$. In the case of the orthogonal cutting, the uncut chip thickness is adjusted with the $z$-axis, and the $y$-axis is fixed. For the planning configuration, the feed and the depth of cut are respectively incremented with the $y$ and $z$-axis.

Using a special developed triggering system, an ultra-high speed camera Photron Fastcam SA-Z, mounted with a Mitutoyo ML $10 \times$ lens, was synchronised with the linear encoder of the $\mathrm{x}$-axis as shown in Fig. 2. The incremental signals in quadrature ( $\mathrm{a}$ and $\mathrm{b}$ ) and their conjugates are interpolated and compared to know the $\mathrm{x}$-position with a resolution of $2 \mu \mathrm{m}$. The cutting tool is observed passing through the $1.14 \times 1.06 \mathrm{~mm}^{2}$ area $(1.783 \mu \mathrm{m} / \mathrm{px}$ with $640 \times 600 \mathrm{px}$ resolution and a 12 bits dynamic range) at a frame rate of $50000 \mathrm{f} / \mathrm{s}$ and an exposure time of $1 / 100000 \mathrm{~s}$. For each trial, a total of 100 frames (denoted $I_{1}$ to $I_{100}$ ) are recorded during cutting. Images $I_{0}$ (initial state) and $I_{101}$ (deformed state) are recorded before and after the cutting test, respectively.

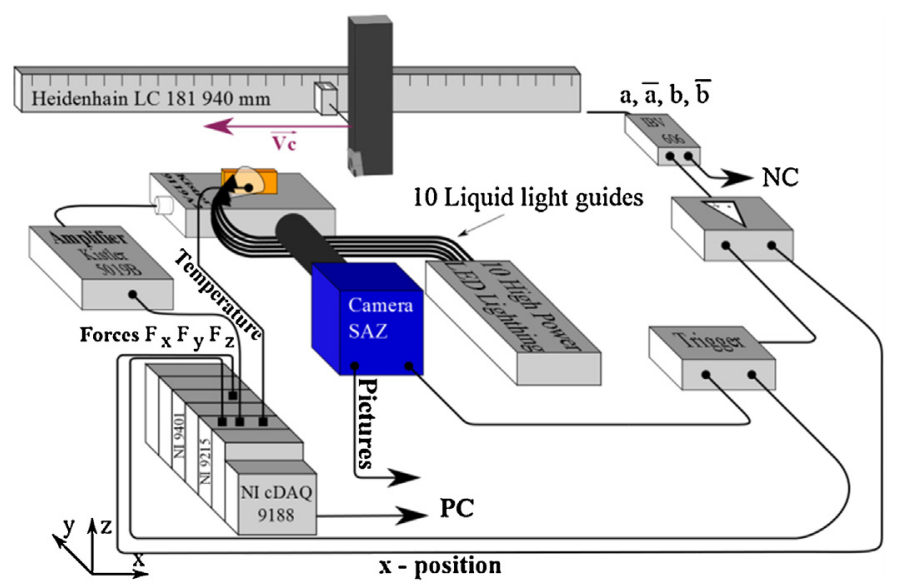

Fig. 2. Planing test set-up.

The DIC was performed on images with CorreliQ4 software that uses a global methodology based on Q4P1-shape functions [11].

A Kistler 9119AA2 piezoelectric dynamometer and a 5019B charge amplifier were used to measure the cutting forces. Finally, a K-type thermocouple was located at $0.05 \mathrm{~mm}$ beneath the machined surface, to measure the inner temperature of the work material.

All signals were recorded synchronously at $10 \mathrm{kHz}$ sampling rate, using a NI cDAQ9188 rack with the NI 9401, NI 9215 and NI 9205 acquisition cards for $x$-position, forces/triggering signals and thermocouple temperature, respectively.

\subsection{Numerical models and parameters}

The Flamant-Boussinesq (FB) analytical model [6,7] describes the kinematic fields induced by a given uniform line load acting over a semi-infinite elastic body. The problem is schematically represented in Fig. 3 and the solution is given by Eq. (1) ( $\lambda$ and $\mu$ are Lamé's coefficients) at any point $M(x, y)$.

$$
\begin{aligned}
u_{x}= & \left.\left.\frac{f_{x}}{2 \pi \mu} \frac{y^{2}}{x^{2}+y^{2}}+\frac{\lambda+2 \mu}{\lambda+\mu} \log \frac{b}{\sqrt{x^{2}+y^{2}}}\right)\right) \overrightarrow{e x} \\
& +\frac{f_{y}}{2 \pi \mu}\left(\frac{x y}{x^{2}+y^{2}}+\frac{\mu}{\lambda+\mu} \arctan \left(\frac{x}{y}\right)\right) \overrightarrow{e x} \\
u_{y}= & \frac{f_{x}}{2 \pi \mu}\left(\frac{x y}{x^{2}+y^{2}}-\frac{\mu}{\lambda+\mu} \arctan \left(\frac{x}{y}\right)\right) \overrightarrow{e y} \\
& \left.\left.+\frac{f_{y}}{2 \pi \mu} \frac{x^{2}}{x^{2}+y^{2}}-\frac{\mu}{\lambda+\mu}+\frac{\lambda+2 \mu}{\lambda+\mu} \log \frac{b}{\sqrt{x^{2}+y^{2}}}\right)\right) \overrightarrow{e y}
\end{aligned}
$$

In the case of orthogonal cutting, the elementary cutting force, $f_{c}=F_{c} / b$ and the thrust force, $f_{D}=F_{D} / b$, can be identified respectively to $f_{x}$ and $f_{y}$ in the analytical model as presented schematically in Fig. 3.

Therefore, knowing the elastic properties of the work material ( $E=201 \mathrm{GPa}$ and $v=0.27,[12])$ and the applied forces, the stress induced in the subsurface can be calculated by successive derivations under plane strain conditions. However, because of the large plastic deformations occurring during the cutting process, the model is only valid in the inner material, below the elasto-plastic boundary, which maximal depth is $p$, as shown in Fig. 3.

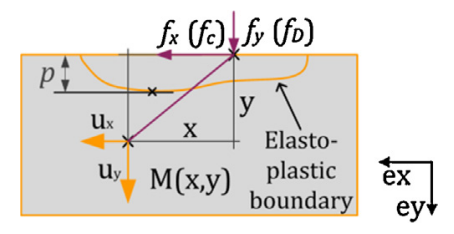

Fig. 3. Parametrisation of Flamant-Boussinesq problem.

As described by Outeiro et al. [3], the equivalent residual plastic strain, $\varepsilon_{\mathrm{eq}}$, within the work material can be determined by DIC, using only two images: $I_{0}$ and $I_{101}$. As a consequence, the maximum thickness of the plastically deformed layer, $p$, generated by orthogonal cutting can be evaluated (see in Fig. 3). This depth and the stress field calculated with the FB analytical model are used to determine the maximal stress at this depth.

In order to predict the plastic limit in the work material for 3Dplaning, the analytical model was applied on each segment from the edge discretisation methodology. Each elementary edge can be seen as a linear edge, acting in an orthogonal cutting configuration [5]. With the linear cutting force model presented in Eq. (2), it is possible to link the 3D geometry of the cutting edge and the

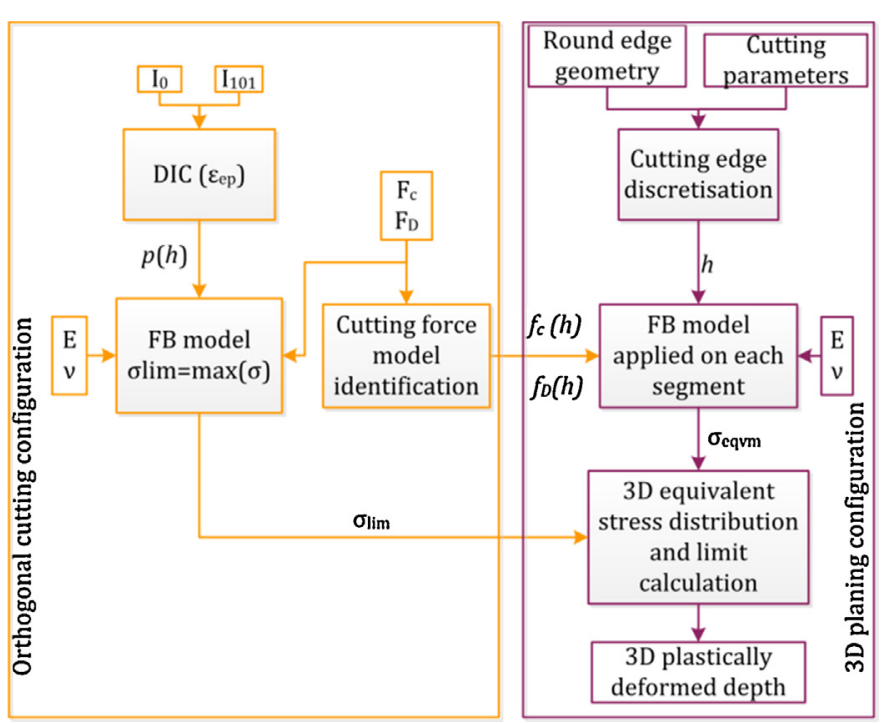

Fig. 4. Flowchart of the proposed hybrid approach. 
elementary forces applied on each segment by calculating the uncut chip thickness, $h$.

$f_{c}=K_{c c} h+k_{e c} \quad$ and $\quad f_{D}=K_{c D} h+k_{e D}$

By applying those estimated line forces in the FB analytical model on each segment, $p$ is estimated in each plane, $i$ (see Fig. 1b) normal to the considered segment. The plastic limit in the work material for 3D-planing generated by the round insert can be finally drawn, as presented in Fig. 1b, by orthogonal projection of the maximal stress value generated by each segment in the $y z$-plane. After all, the resulting plastic depth remaining on the material after the 3D-planing is the maximal depth generated by the round edge, calculated in the $z$-direction. The flowchart of this hybrid approach is presented in Fig. 4.

\section{Results and discussion}

\subsection{Cutting forces modelling}

An inverse identification procedure has been applied to determine the mechanistic law coefficients (see Eq. (2)), for the orthogonal cutting configuration, by least mean squares method between the mean measured forces and the modelled one. Table 1 shows the values of these coefficients, the maximum and the average relative errors $\left(R E_{\max }\right.$ and $\left.R E_{\text {mean }}\right)$. The low values of $\mathrm{RE}_{\text {mean }}$ (only 6.3\% and 6.5\%) show the effectiveness of this model for the cutting and thrust forces prediction. The relatively high values of $\mathrm{RE}_{\max }$ were obtained for $h=0.01 \mathrm{~mm}$ and can be explained by the low ratio between the uncut chip thickness and the cutting edge radius $\left(h / r_{n}\right)$, where the ploughing phenomenon is competing the cutting. This value of $h$ will no more be taken into consideration in the analysis hereafter.

Table 1

Cutting force model coefficients and accuracy.

\begin{tabular}{lllll}
\hline Force direction $(i)$ & $K_{c i}(\mathrm{~N} / \mathrm{mm})$ & $k_{e i}\left(\mathrm{~N} / \mathrm{mm}^{2}\right)$ & $\mathrm{RE}_{\max }(\%)$ & $\mathrm{RE}_{\text {mean }}(\%)$ \\
\hline Cutting $(c)$ & 3235 & 43.5 & 18.3 & 6.3 \\
Thrust $(D)$ & 2135 & 96.1 & 18.7 & 6.5 \\
\hline
\end{tabular}

\subsection{Determination of the stress limit criterion $\sigma_{\text {lim }}$}

As shown in Fig. 5, $\varepsilon_{\text {eq }}$, is larger near to the surface and decreases as the depth beneath the machined surface increases. Then, $\varepsilon_{\mathrm{eq}}$, stabilises around a nonzero value due to the measurement noise of the DIC. In order to locate the limit depth between the elastic and the plastic regions, an equivalent plastic strain criterion of 0.0065 was used. This value represents the mean equivalent strain at $1 \mathrm{~mm}$ behind the generated surface plus three times the standard deviation.

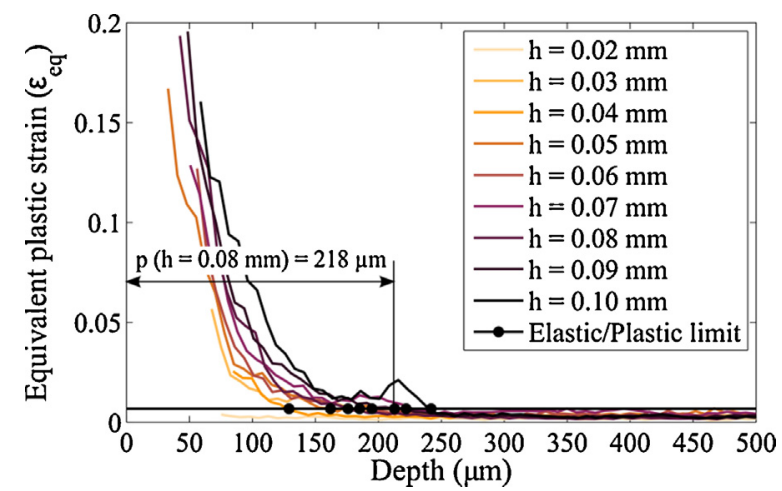

Fig. 5. Determination of the plastically affected depth with the equivalent strain calculation for orthogonal cutting tests.
Knowing, both the depth and forces for each trial, it is now possible to calculate the maximal stress generated by the cutting and the thrust forces at this depth with the FB model, as shown in Fig. 6. A temperature value of $43{ }^{\circ} \mathrm{C}$ was used in the calculations of the elastic properties, which was obtained from the measurements performed by the K-type thermocouple. This protocol has been performed for all the 30 orthogonal cutting tests leading to an identified limit stress criterion $\sigma_{\mathrm{lim}}=1307 \mathrm{MPa}$ with a standard deviation of $85 \mathrm{MPa}$.

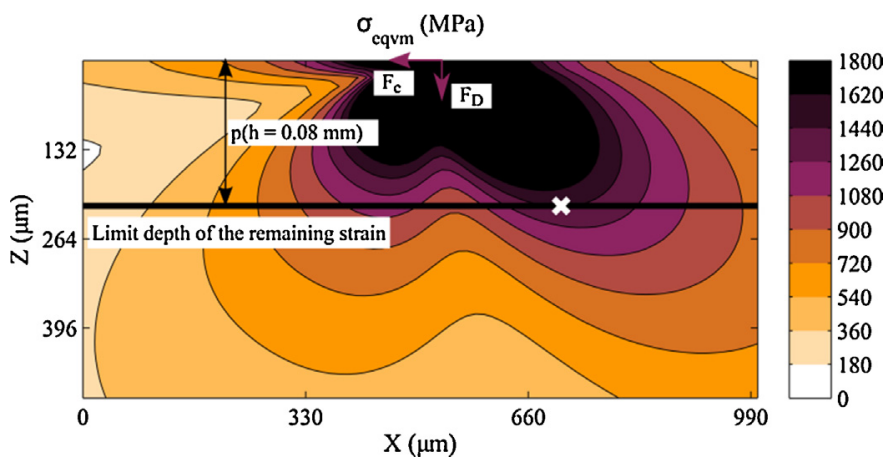

Fig. 6. Distribution of Von Mises equivalent stress in the work material for the orthogonal cutting test $(h=0.08 \mathrm{~mm})$, obtained by the FB model.

\subsection{D modelling validation and surface integrity prediction}

Fig. 7 represents the distribution of the predicted elastic Von Mises equivalent stress in the work material. For each active cutting edge segment, the uncut chip thickness has been calculated at the middle of the segment, where the cutting and thrust forces were applied.

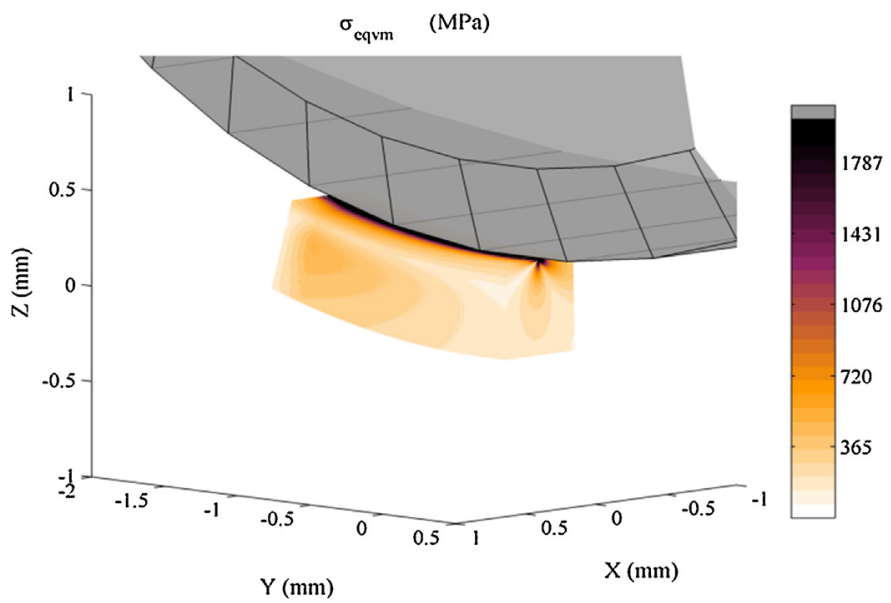

Fig. 7.3D representation of the Von Mises equivalent stress $\left(\sigma_{\text {eqvm }}\right)$ field in the work material induced by a cutting edge discretised with 800 segments.

Fig. 8 represents the maximum Von Mises stress projected in the $y z$-plane, where the plastic deformed region $\left(\sigma_{\text {eqvm max }}>\sigma_{\text {lim }}\right)$ is coloured in black. For $f=0.2 \mathrm{~mm}$ and $a_{p}=0.2 \mathrm{~mm}$, the predicted residual strain limit depth beneath the machined surface is $79 \mu \mathrm{m}$.

In order to validate the 3D-planing model, Vickers microhardness measurements were performed on five cross-sections parallel to the $y z$-plane. A matrix of $25 \times 50$ indentations with $100 \mathrm{~g}$ load ( $50 \mu \mathrm{m}$ length between each) was applied to measure the hardness distribution in each cross-section. The average hardness value of the five indentations at the same position in the matrix was calculated. Therefore, a single matrix of average hardness was obtained, over which a 4 th order polynomial surface was interpolated to obtain the isolines shown in Fig. 9. The $620 \mathrm{HV}_{0.1}$ isoline represents plastically deformed layer regards to the value measured within the specimen $\left(610 \mathrm{HV}_{0.1}\right)$. Finally, the 


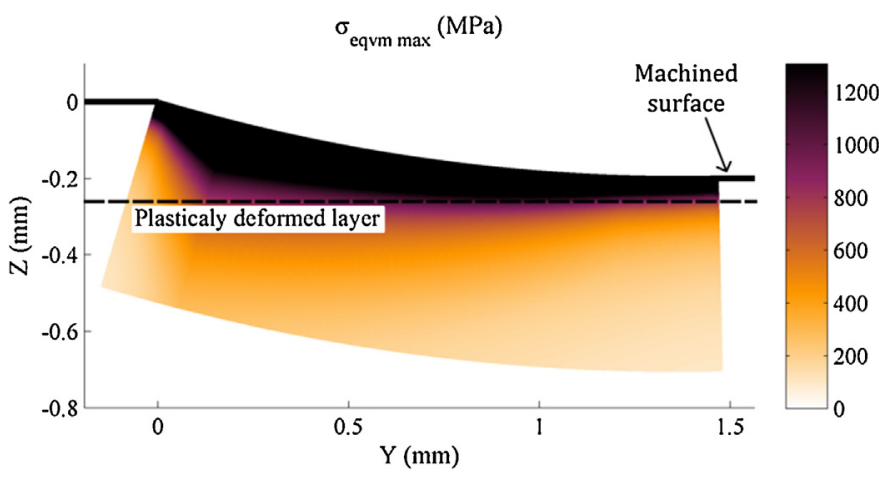

Fig. 8. Maximal stress in the $y z$-plane. Stresses values higher than the stress criterion are represented in black.

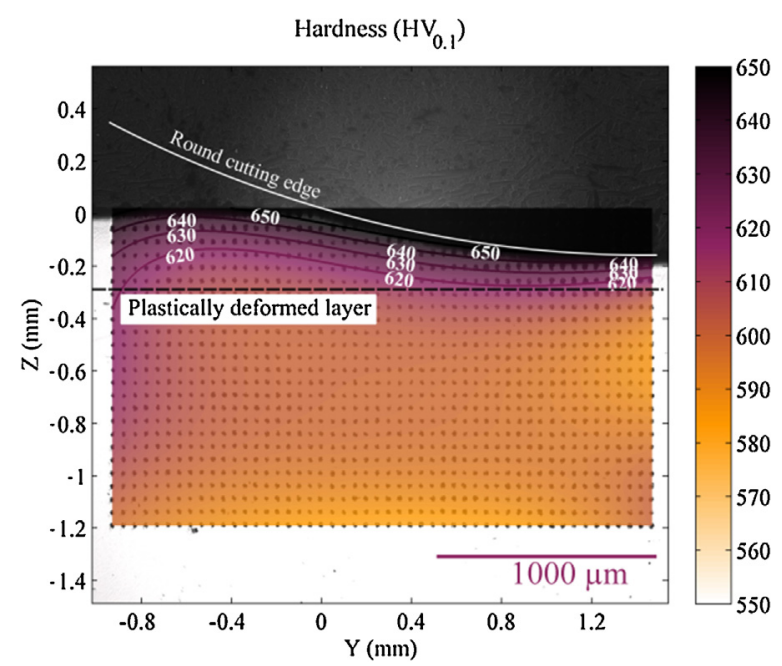

Fig. 9. Mean hardness measurements in the specimen after 3D-planing (cutting conditions: $f=0.2 \mathrm{~mm}, a_{p}=0.2 \mathrm{~mm}, V_{c}=90 \mathrm{~m} / \mathrm{min}$ )

maximum thickness of plastically deformed layer induced by the 3D-planing was estimated, being equal to $87 \mu \mathrm{m}$. This depth was calculated the same manner as the stress criterion in the 3D modelling.

The model predictions are in quite good agreement with the measurements. It just slightly under-estimates in 5.5\% the thickness of the plastically deformed layer. Furthermore, both predicted and measured distributions are very similar, showing the effectiveness of the proposed modelling approach for predicting the plastically deformed affected depth.

\section{Conclusion and outlooks}

An innovative hybrid experimental/analytical approach was developed and applied for predicting the plastically deformed affected depth induced by hard machining of AISI 52100 bearing steel. This approach combines the commonly used cutting edge discretisation methodology with the Flamant-Boussinesq analytical model and the kinematic (displacement and strain) field analysis performed by DIC. Two kinds of metal cutting configurations were used in this approach: orthogonal cutting and 3D-planing.

Firstly, the orthogonal cutting tests permitted to obtain the equivalent plastic strain distribution in the work material, which was calculated by Digital Image Correlation (DIC). Based on this distribution, the plastically deformed depth was determined and used together with the measured forces as input data for the Flamant-Boussinesq model. This one permitted the knowledge of a limit stress criterion for the plastic region. In addition, the orthogonal cutting tests were used to identify the cutting and thrust forces model.
Secondly, using the cutting edge discretisation method, the predicted forces induced by a round edge were applied to each edge segment. Then, the Flamant-Boussinesq analytical model was applied to each edge segment in order to calculate the stress field induced in the work material. In view of the determined stress criterion, the threshold between the plastic and elastic regions is defined and the thickness of the plastically deformed layer is predicted.

Finally, Vickers micro-hardness tests were performed to verify the accuracy of the proposed model. A 5.5\% deviation between the predicted and the measured maximum thickness of plastically deformed layer was obtained along the $87 \mu \mathrm{m}$ affected layer.

Based on the Flamant-Boussinesq model results, an improvement is proposed, which consists into use this model as shape functions for the DIC calculation instead of Q4P1 functions.

Furthermore, the kinematic field and the cutting forces measurements should be used for the validation of multiphysics numerical simulations. Moreover, the cutting operation can be seen as a mechanical test, used to identify the material constitutive model coefficients based on an inverse approach. In addition, the thermal field measurements should be taken into account for more realistic material behaviour.

\section{Acknowledgements}

The authors gratefully thank:

- ADEME for the financial support through the WindProcess project;

- NTN-SNR for material supply;

- François Hild for his help on DIC, Sébastien Campocasso for his help on experimental set-up and Guillaume Fromentin who initiated the study.

\section{References}

[1] Jawahir IS, Brinksmeier E, M'Saoubi R, Aspinwall DK, Outeiro JC, Meyer D, Umbrello D, Jayal AD (2011) Surface Integrity in Material Removal Processes: Recent Advances. CIRP Annals - Manufacturing Technology 60(1):603-626.

[2] Arriola I, Whitenton E, Heigel J, Arrazola P (2011) Relationship Between Machinability Index and In-process Parameters During Orthogonal Cutting of Steels. CIRP Annals - Manufacturing Technology 60(1):93-96.

[3] Outeiro JC, Campocasso S, Denguir L, Fromentin G, Vignal V, Poulachon G (2015) Experimental and Numerical Assessment of Subsurface Plastic Deformation Induced by OFHC Copper Machining. CIRP Annals - Manufacturing Technology 64(1):53-56.

[4] Armarego EJA, Whitfield RC (1985) Computer Based Modelling of Popular Machining Operations for Force and Power Prediction. CIRP Annals Manufacturing Technology 34(1):65-69.

[5] Campocasso S, Poulachon G, Costes J, Bissey-Breton S (2014) An Innovative Experimental Study of Corner Radius Effect on Cutting Forces. CIRP Annals Manufacturing Technology 63(2):121-124.

[6] Flamant M, Boussinesq M (1892) Equilibre d'élasticité - Sur la répartition des pressions dans un solide rectangulaire chargé transversalement. Compte Rendu de l'Académie des Sciences 114(11):1465-1468.

[7] Boussinesq M (1892) Equilibre d'élasticité - Des perturbations locales que produit au-dessus d'elle une forte charge, répartie uniformément le long d'une droite normale aux deux bords, à la surface supérieure d'une poutre rectangulaire et de longueur indéfinie posée de champ soit sur un sol horizontal, soit sur deux appuis transversaux équidistants de la charge. Compte Rendu de l'Académie des Sciences 114(11):1510-1516.

[8] ISO 683-17 (2014) Heat-Treated Steels, Alloy Steels and Free-Cutting Steels Part 17: Ball and Roller Bearing Steels. Afnor 1-37.

[9] ISO 3002-1 (1993) Basic Quantities in Cutting and Grinding - Part 1: Geometry of the Active Part of Cutting Tools - General Terms, Reference Systems, Tool and Working Angles, Chip Breakers. Afnor 1-68.

[10] Baizeau T, Campocasso S, Fromentin G, Rossi F, Poulachon G (2015) Effect of Rake Angle on Strain Field During Orthogonal Cutting of Hardened Steel with c-BN Tools, Procedia CIRP 31(0):166-171.

[11] Besnard G, Hild F, Roux S (2006) "Finite-Element” Displacement Fields Analysis from Digital Images: Application to Portevin - Le Châtelier Bands. Experimental Mechanics 46(6):789-803.

[12] Ding H, Shin YC (2013) Multi-Physics Modeling and Simulations of Surface Microstructure Alteration in Hard Turning. Journal of Materials Processing Technology 213(16):877-886. 